\title{
Early childhood Education and Public Care Policies in Chile: A Historical Perspective to Analyze the Present
}

\author{
Maria Victoria Peralta \\ Central University \\ Chile
}

\begin{abstract}
Comparative studies in public policy is, in general, an important area, suitable for deep analysis, since it indicates how the State creates a hierarchy of different development sectors that have an impact nationwide, as well as telling us exactly what the end policy product is. With this in mind, the analysis of these policies in emerging countries becomes a particularly interesting field, since it implies that some prioritizations in economical and social contexts are not relatively complex. In this sense, as part of Latin America, Chile is an interesting case to analyze, since in its earliest years as a republic it was concerned about early childhood education. This means that since the first experiences in the 19th Century, an institutional legal basis has been created in the ECEC field. This has made it possible to establish increasingly challenging public policies as seen in the recently created social protection program, "Chile Crece contigo" (Chile Grows with You). This article aims at providing a historical account of the development of public policies in this field, by analyzing their origins and most particularly, their present status. This current situation allows Chile to assist $50 \%$ of the population of those aged 0 to 6 in various institutions and in different ways, mainly with public funding (83\%).
\end{abstract}

Key words: early childhood education and care (ECEC), ECEC public policies, ECEC history

\section{Introduction}

Chile has been acknowledged worldwide as having advanced state-of-the-art policies for Early Childhood Education and Care. In fact, during President Michelle Bachelet's government (2006-2010), significant measures were taken and became known internationally, as the creation of the "Chile Grows

Correspondence concerning this article should be addressed to M. Victoria Peralta, Professor and Director of the International Institute for Early Childhood Education (Directora Instituto Internacional de Educación Infantil, Facultad de Ciencias de la Educación) at Central University, Sta. Isabel 1278 of. 403, Santiago de Chile. Electronic mail may be sent to mvperaltae@ucentral.cl with You" Social Protection Program, which provides comprehensive care for boys and girls who are socially vulnerable since birth. This includes free Access to Nursery Schools of the public sector in addition to other services. Although this indicates that progress has been made, other improvements are being made in the present government of President Sebastián Piñera (2010-2014), such as extending the maternity leave period to six months. These achievements have been possible due to an increasing and permanent concern the country has had through different governments and across different political parties for over a hundred and fifty years.

This paper aims at providing a review of the historical development of public policies for early 
childhood development, starting from a brief account of the early 19th Century, to a subsequent analysis of the present situation through its institutions and programs, with a special emphasis on the development of the educational components of this system.

\section{The Beginning}

\section{The First Initiatives in the 19th Century}

The first educational initiatives for preschoolers in Chile arose in the Republican period (as of 1810) as a result of the concern of the first presidents about educating the people at the end of the settlement period, at which point most were illiterate.

Minister of Public Education Manuel Montt's initiative of sending the outstanding Argentinean scholar Domingo F. Sarmiento to personally observe the progress made in educational matters in Europe (1845-1847), to generate public policies, had a number of major effects. In fact, the report written by $\mathrm{Mr}$. Sarmiento, "On Popular Education", has an entire chapter on proposing regulations for opening an "Infants' Asylum", an institution he had visited in France and by which he had been impressed.

However, the urgent educational needs of the country caused the implementation of this proposal to be delayed by some decades, and it was not until 1864 that the first "Nursery School" opened by a decree of the Ministry of Public Education and financed with fiscal funds. The administration and teaching duties were taken over by Catholic nuns of the Sisters of Charity congregation, although later on they were supported by teachers trained at the first Teacher Training School for women.

At the same time that this initiative was undertaken, among the many educational debates taking place in the country, an increasing interest in early childhood education and care started to arise, stimulated by the visits to Europe by important scholars within the field of Chilean education, such as the educational reformist José Abelardo Núñez (1879-1882), the scholar Valentín Letelier (1881), and educators Mr. Juan Madrid and Mr. José Muñoz Hermosilla (1884).

After the first two "preschool centers" were promoted by the Government, the private sector, especially the Germans and American immigrant communities became interested in preserving their language, culture and religion, and opened the first "kindergartens" with Froebelian influences. The first Chilean kindergartens then opened, and were initially and significantly subsidized with fiscal funds.

\section{The First Public Policies in the Early 20th Century}

The first entirely and publicly funded Nursery Schools were of three types: Preceptor Normal Schools annexes that served as application and teaching practice centers for the teachers; Girls' High School annex kindergartens located in the major cities of the country; and High School annex kindergartens.

Among these, the one having a significant role due to the influence it had on the development of this level was the kindergarten of the Normal Teacher Training School $N^{\circ} 1$ of Santiago. This was due to the active leadership of Principal Mrs. Leopoldina Maluschka and the graduated kindergartenians, who carried out activities that motivated the sector to create and develop new kindergartens, besides undertaking the first specialized publications and organizing unions.

In terms of public policies, this meant that eventually, after over half a century of debate on the issue of opening kindergartens, the State of Chile committed resources and measures to officially start work at this educational level.

However, after preschool began in the public sector during the peak period between 1906 and 1913, which meant that for the Centennial of the Republic (1910), nearly 1000 children in 50 kindergartens were being educated throughout almost the entire country, came a period of major economic difficulties that almost saw the disappearance of these schools. 
Pre-school education in the public sector started to recover in the 20's after these problems, as part of the Educational Reform of the period from 1927 to 1930, whose basic purpose was the opening of the "New School" in Chilean schools. Thus, new classrooms were opened and Maria Montessori Ovidio Decroly methods were applied to enrich the education on offer further.

From then on, the Chilean public sector preschool experienced various periods of higher or lower peaks over different governments. In growing peak periods there were important policies, regulations, programs and institutions which, if analyzed over time, go a great way towards explaining the current development of education at this level. Among the factors that promoted the growth of this sector and the generation of public policies was the participation of professional people within this field. The influence this contribution had at different stages is detailed below.

The Training of Specialized Professionals and Its Impact on the Sector's Development

In the 19th Century, the first preschool centers were assisted by nuns and primary school teachers with only a very basic knowledge of the work at this level. Specialized training started in 1906 when the Chilean government hired Leopoldina Maluschka, a kindergarten teacher who had graduated from the Graz Teacher Training School and music teacher graduated from the Viena Conservatory (Austria).

The first specialized teachers in the Froebelian method were trained at the Teacher Training School $\mathrm{N}^{\circ} 1$ of Santiago who, together with their mentor, soon started a "nationalization" of this proposal.

Training of these teachers was theoretical-practical, focusing on 3- to 6-year-old children to work primarily in preschool centers, a focus that was later followed by other public and private Teacher Training Schools, making it a characteristic of this stage.
A great change came in 1944, when the main public university of the country created the Preschool Teacher Training School of the University of Chile. This training school was led by prestigious professionals as Amanda Labarca and Matilde Huici. With the participation of professors of different areas, namely, psychology, health, nutrition, arts and education, started a training period characterized by a comprehensive and mainly educational approach to work with children from birth to the age of six.

Important initiatives started to take shape around this university center: research, seminars, publications and specialized professional organizations and, particularly, the extension to serve children in nontraditional fields such as hospitals, industries and public housing projects.

The importance influence this university institution had through its professors and graduates forced different governments and politicians to acknowledge and request its technical assistance, thus generating important public initiatives through such contributions. Among these were the creation of new institutions to serve children, the development of official preschool programs, support technician training, and various specific regulations and laws. Among the latter, Law 17.301, enacted in 1970, should be highlighted. This law created the main institution to serve preschoolers, the National Commission of Nursery Schools. This institution also became the main legal body accredited for this field.

At present, preschool teacher training is done throughout the country in various Professional Institutes and Universities. There also are graduate level Master's degree courses in the field. These professionals work in different public and private services of the country in management positions or directly with preschoolers, and have made it possible to develop better quality service within the limitations that Chile has as an emerging country. 


\section{The Present Legal and Institutional Situation, Policies and Programs of the Sector}

\section{Official Definition of Early Childhood Education and Care}

The official definition for the Chilean early childhood education and care is provided by the General Law on Education of 2009, Article 18 of which states that:

\begin{abstract}
"Early childhood education and care is the educational level that assists children, on a comprehensive basis, from birth to the time they enter elementary school, not being a requirement for the latter. Its objective is to favor systematically, promptly and pertinently the comprehensive development and relevant and significant learning in preschoolers, in accordance with the curricular bases determined as provided by this law, and give assistance to the family in its irreplaceable role as the first educator."
\end{abstract}

This concept comprises the centennial historical conception that the Chilean early childhood education and care system has had in terms that it starts from birth and that its approach is designed to be comprehensive in nature.

\section{Early Childhood Education and Care as an Institution}

In Chile, the present Early Childhood Education and Care system is mainly provided through programs funded by the State (83\%). In the public sector, the main service modes are: groups of preschoolers in school directly subsidized by the Ministry of Education, and in schools and programs of both the National Board of Nursery Schools (JUNJI) and the Integra Foundation. Below is a description of each of these institutions, with their specific policies for the programs:

\section{Ministry of Education}

In accordance with the legislation in force, this Ministry controls, inspects and supervises. Its powers of control and inspection are centred on primarily administrative areas of work: compliance with the requirements for the official registration of the schools, as well as compliance to award and keep the state subsidies provided to the subsidized schools in the country. Supervision relates mainly to the technical teaching work of the Ministry supervisors.

Regarding the programs it supports in the field of early childhood education and care, it this relates primarily to subsidies to both municipal and private schools in the first Transition level (4 to 5-year-olds) and the second Transition level (5 to 6-year-olds) and to a lesser extent, "Nursery Schools" (4 to 6-year-olds). This funding, which is approved on a yearly basis by the Budget Law, is overseen by the Educational Subsidies Unit, and corresponds to the monthly unit value subsidized per student.

Service to children is provided by early childhood educators in duly furnished rooms in schools nationwide, through educational curricula the teachers develop from the diagnostics of the individual characteristics and needs of the children, families and communities, and based on the guidelines of the official curriculum: Curricular Bases of Early Child Education and Care. Specialized supervision is also available.

\section{National Board of Nursery Schools (J.U.N.J.I.)}

The National Board of Nursery Schools is an autonomous corporation, with legal status in public law, funded by the State, whose management is decentralized and is related to the government through the Ministry of Education. It was created in 1970 by Law $N^{\circ} 17.301$, as part of an Educational Reform.

The mandate of this institution is to generate, promote, organize and supervise nursery schools, whether private or public, around the country. Initially, it was created as a managing public entity in this field, with representatives of all the fields related to early education and care, and would propose, coordinate and oversee all the policies for this field. 
After some time, during the Military Regime (19731989), it was partly deprived of this power, and had to report to the Ministry of the Interior. Thus, it's educational role decreased and it became an entity more involved in providing assistance than anything else.

During the return to democracy (1990), its managing role was strengthened so that it became a more specialized entity delivering quality early education and care programs. It also promoted a major line of new programs that enabled the needs and individual features of children and families of the more vulnerable sections of the population to be served. Thus, educational programs were created for infants under the age of three whose mothers were working at home (Day Care Center at Home), for children of semi-rural or rural families (Family Nursery Schools), for communities, families and children pertaining to all Chilean indigenous people, for infants whose mothers work in seasonal jobs as harvesting, tourism, etc. (Seasonal Nursery Schools), for children in families of highly dispersed population areas through the "Distant Nursery School" program among other specially created nonformal modes. In addition to this, the number of classical Day Care Centers and Nursery Schools increased nationwide, and an educational assessment system of the various educational programs was created. (EVALUA)

At present, the JUNJI Board mission is to: "provide quality early childhood and care to children preferably under the age of four, who live under conditions of social vulnerability, in the framework of the "Chile Grows with You" Protection System for the Early Childhood, in order to guarantee their personal development with equal opportunities through the creation, promotion, supervision and certification of day care centers and nursery schools managed directly or by third parties"1.

\section{Current Early Childhood Education Programs Developed by the JUNJI Board}

The aforementioned programs have been reformulated and are currently organized as stated below ${ }^{2}$ :

\section{Nursery School Program}

Implemented in specially designed educational establishments, it serves infants aged 0 to 4 and includes children with special needs. It is directly managed by the JUNJI Board or under the mode of fund transfers to municipalities or non-profit entities. They are located in urban and semi-urban areas. They are open 11 months a year full time, and offer a free school meals service.

\section{Alternative Programs}

Of a face-to-face nature, they are managed by an early education and care technician. They are open every day and serve infants from the age of two until entrance to elementary school. They offer a free comprehensive service, comprising education, food and social care. They consider the family as the key player in the educational process and are preferably located in rural or semi-urban areas. There are different types:

- Family Nursery School: Open part time, managed by a nursery school technician with the help of the children's families.

- Labor Nursery School: Aimed at children whose mothers work, and organized according to their needs. It offers extended working hours and food, accordingly.

- Seasonal Nursery School: Aimed at children whose mothers have temporary or seasonal jobs, especially in fruit production, farming, fishing and tourism. It is open three or four months in summer.

- Intercultural Nursery School: For children between two and five belonging to different indigenous groups. An intercultural curriculum is utilized .

- Infant Service Improvement Program (PMI): For children in socially vulnerable circumstances. In community centres with the participation of 
the family and cultural agents who, with the support of JUNJI Board professionals, provide them with pro bono education and care.

\section{Family Programs}

The main assumption of this program is that the family is the leading player in the educational process of children and that this takes place mainly in their own home. The infants' homes become educational spaces, since parents or close relatives are the guides in the learning process with supplementary help given by early childhood educators and teaching aids.

- Communication Program: For children not attending formal programs because the live in highly dispersed population areas. It was developed through radio broadcasts supplemented with educational booklets for their families and visits to their homes by professionals to support and assess the learning process.

- Know-Your-Child Program: This program trains mothers who live in rural areas and nurtures them as trainers of other mothers to become educators of their own children under the age of six at home.

\section{Integra Foundation}

The Integra Foundation is a non-profit private entity created in 1990 from the National Foundation of Aid to the Community created during the military regime. Over the course of the different governments of the democratic period, its role to provide comprehensive service to infants has been strengthened, especially in terms of education, which traditionally was it's weakest area. The body to which it reports was changed from the Ministry of the Interior to the Ministry of Education .

At present, it is a national network of human resources and infrastructure working in the area of early childhood. It is part of the Presidency's
Foundations Network, chaired by the First Lady. It has an Executive Director, a National Executive Committee, and a Council integrated by different entities related to this field.

Its mission is to: "Achieve the comprehensive development of children from the age of three months to four years living in poverty and in social vulnerability through a high quality educational program incorporating the families and the community, and promoting infants' rights in a context of democratic coexistence." 3

Its main programs are:

Nursery Schools, for children between the ages of three months and four years taught by early childhood educators and nursery aids. They are open full time and provide comprehensive care. It is applied to the institutional educational program together with other programs as the Digital Project through which computers are installed in rooms for children between the ages of two and four to use in order to promote expected learningoutcomes.

Nursery School on Wheels is a travelling school which travels through the rural areas of the country taking the nursery school to those places where poverty, low population density, and geographical dispersion prevent the establishment of one.

Pehuenche Summer Camps, for Pehuenche (indigenous people) children attending INTEGRA Foundation nursery schools of the area on a regular basis, who join their families in the mountains during summer. The educational activities are moved to the places where they camp.

Psychological and Social Assistance to Hospitalized Children and Their Families. This program works with children aged 3 months to 5 years who are sick and have to spend some time in the pediatric or surgery units of the public health system of Chile.

\section{Public Policies for the Field}

Since the return to democracy (1990), a set of policies have been favored by the Ministry of Education over the course of different governments, which have been taken over by the aforementioned 
public institutions, and applied according to their characteristics and programs. These policies basically include:

- Service coverage increase with a view to equality,

- Improvement of the quality of the service rendered in the various programs

- Improvement of the institutional management for an efficient achievement of the desired goals

Service coverage increase with an equality approach

The increase in service coverage has been carried out over the past 20 years with an view to equality, which has meant focusing on those infants coming from the most socially vulnerable families of the country. For this purpose, the JUNJI Board and the INTEGRA Foundation prioritize the intake of infants under the age of four to the program that best meets the needs of the infants and their families. At the same time, children with special needs and those children of homemaker mothers have special priority enshrined in law. In schools subsidized by the Ministry of Education, the access of children of ages 4 to 6 is guaranteed.

The set of policies, institutions and programs described above, together with the contribution of the private sector have resulted in the early childhood education and care level growing steadily since 1990, doubling the number of children receiving education and care. The latest official figures available based on the CASEN Social Survey applied by the Ministry of Planning corresponds to 2008. The coverage goal change is shown below:

From these data, it is estimated that by 2011, gross attendance is likely to be over $50 \%$, with a significant increase in the segment under two years due to the construction of 900 Day Care Centers during Michelle Bachelet's office term. The latter measure is the result of a specific policy set for that period. This percentage is rather good relative to Latin American indices ${ }^{4}$ due to the fact that over half of the infant population from ages 0 to 6 is served through different programs and because of the stability increasing nature of funding which is included in the national budget.

\section{Service quality improvement}

This policy has been developing steadily since 1990 through various initiatives such as the provision of training to the supervising staff and the execution of different programs. The adultchild quotient as well as the quality of the educational material has been improved. This received special attention since the new national official curriculum was approved by a decree of the Ministry: The Curricular Bases of Early Childhood Education and Care (October, 2001). 5 This document was designed with the participation of stakeholders across the entire field, and aims to guide the establishment of an infants centred pedagogy for the 21st Century according to emerging national realities. Therefore, this has required the generation of important paradigmatic and didactic changes, whose impact continues to create a favorable atmosphere.

A three-phase program was designed for its initial implementation:

The first phase focused on early childhood educators and their educational communities. They had to analyze, personalize and give new meaning to the basic premises of the Curricular Bases with respect to their own pedagogical practices. For this purpose, quality was improved with the participation of the country's universities and it was extended across the entire field. "Model Reform Centers" were then opened in the three official institutions: Schools and Nursery Schools of the JUNJI Board and the Integra Foundation, in addition to a number of private institutions, all done in order to offer some models of initial implementation as seen from the reality of the country's institutions. The experience of 
Table 1

Net and gross attendance rates in early childhood education and care (0 to 6 years)

\begin{tabular}{cccccccccc}
\hline Attendance & 1990 & 1992 & 1994 & 1996 & 1998 & 2000 & 2003 & 2006 & 2008 \\
\hline Net & 15.9 & 18.9 & 21.7 & 23.7 & 24.8 & 26.8 & 29.9 & 38.9 & 37.4 \\
\hline Gross & 22.2 & 27.0 & 28.9 & 32.5 & 32.6 & 35.5 & 37.4 & 46.0 & 45.0 \\
\hline
\end{tabular}

\begin{tabular}{|l|l|l|l|}
\hline $\begin{array}{l}\text { Phase 1: } \\
\text { Establishment of } \\
\text { fundamentals and } \\
\text { basic concepts of } \\
\text { B.C.E.P }\end{array}$ & $\begin{array}{l}\text { Phase 2: } \\
\text { Curricular } \\
\text { implementation: } \\
\text { Design, Application } \\
\text { and Assessment }\end{array}$ & $\begin{array}{l}\text { Phase 3: } \\
\text { Curricular } \\
\text { diversification } \\
\text { and specific } \\
\text { didactics }\end{array}$ \\
\hline
\end{tabular}

Figure 1. Phases for the Implementation of the Early Childhood Education and Care Curricular Reform First stage of Curricular Establishment 2002-2006.

this stage was systematized and monitored, and the results were then published and shown on video.

The second phase addressed in a broader way the establishment of a quality curriculum with all its Learning Contexts at the various levels and utilizing groups of infants. This implied the application of particular criteria for Planning, Educational Community Formation, Organization of Educational Spaces, Timing Organization and Assessment in the different institutions. For this purpose, work was started in the sector and was subsidized by the Ministry of Education from the "Reference Schools" that could be visited, as a way of stimulating a more extensive establishment of the curricular reform in other Nursery Schools and Implementation Schools in all regions.

The third phase: the "Curricular Diversification" phase, focused on the incorporation of the needs of each educational community in the curricula in the implementation stage, Educational Information Technology, Interculturality, Special Educational Needs, Motor Function and Healthy Life, among others. The main strategies utilized were the improvement and the provision of diversified programs and materials.
Since 2006, institutions have continued with "the elaboration of other technical instruments that have operationalized this national curriculum to its own needs, in addition to the improvement in the contexts of different issues and especially in the assessment of desired learning outcomes." Progress can been seen in both language and math. However, additional work needs to be be done in terms of more complex and challenging ways to fully empower the child.

\section{Modernization of institutional management}

This policy, which is concomitant to the previous policies, has been essential for public institutions over the course of the different governments to achieve better efficiency in the provision of core coverage and quality policies. For this purpose, seen especially in the JUNJI Board and the Integra Foundation, management systems have been developed to focus on the decentralization and modernization of administrative processes. At the same time, a law has been passed in Congress to create a Superintendence and an Agency for Quality in Education, which will oversee all educational levels. 
Policy for the incorporation of early childhood programs: "Chile Grows with You."

The policies for the protection, health and education during early childhood historically developed by Chile, as well as their progressive and acknowledged achievements through various indicators such as education and health, (see exhibit on infant mortality), have been develping over some time a major network of better conditions for the development of new generations. This situation has made it possible for President Bachelet's administration (2006-2010) to foresee that making progress in this issue was important by incorporating the different policies of the field, along with new contributions, to create a system for early childhood programs and thus achieve better synergy of all these measures.

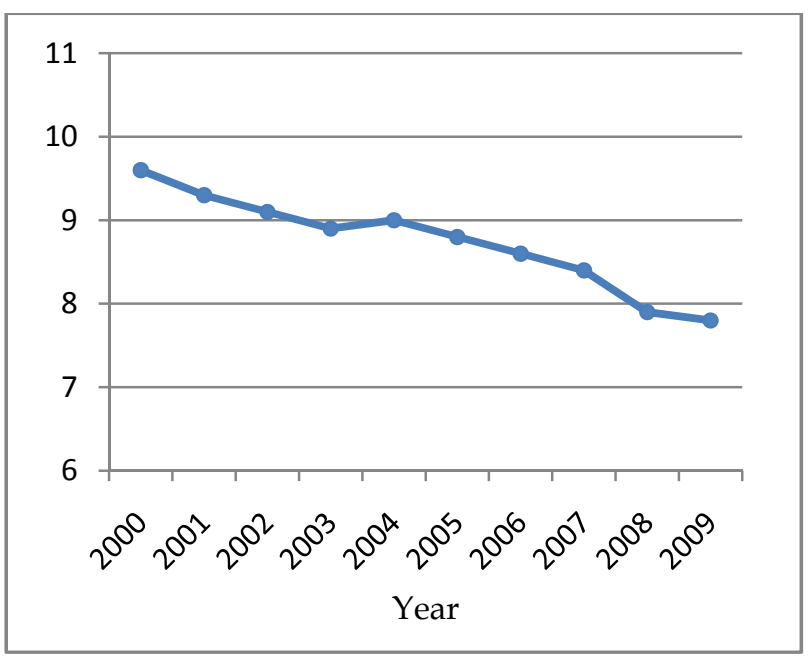

Figure 2. Chile Infant Mortality Decrease (2000-2009)

Thus, the creation of the "Chile Grows with You" program was set as a core policy for early childhood, and different initiatives have been implemented since then. Following this, it was established as a CrossSector Social Protection System in September 2009 through Law 20.379, and it became a stable public policy designed to strengthen the progress already made. The said law states that children join "Chile Grows with You" as of their first gestation medical check-up in the public health system. They are accompanied and supported during their growth until they enter the school system. Additionally, guarantees of access to technical assistance, day care centers, nursery schools and the Supportive Chile Program are established for those families from the most socially vulnerable situations. Likewise, a preferred access scheme was established for such families to the entire service network of the State.

Among the major aids the System provides are some general initiatives aimed at the entire early childhood education and other initiatives aimed specifically at the entire early childhood population assisted by the public health system. For the latter group, it provides general support and additional aid according to specific needs. Thus, it provides special support to children showing major social vulnerability and belonging to households of the $40 \%$ lower income range in the country. The services offered are detailed below:

Massive Educational Program, given through different media: nationwide radio program broadcast on a weekly basis; TV program broadcast in waiting rooms of medical centers; a specialized phone service and website; educational cards, supporting music and children's tales collection and an electronic bulletin.

Support Program for Psychological-Social Development.

It is the axis or access program to the Chile Grows with You sub-system, developed by the public health system, and aimed at children assisted by the public health system. It is undertaken by the Ministry of Health through its 29 Health Services. It is the entry to the Chile Grows with You program, and offers intensive support for the control, monitoring and promotion of early childhood health from gestation to the age of 4 . 
Specific Service According to Children's Particular Characteristics.

These are programs and services that the System supplies to the early childhood population and their families being assisted by the public health system and showing social vulnerability indices. The said services are organized and managed through the Chile Grows with You Network of the borough where they live, and are divided into two groups:

\section{Guaranteed Services that Comprise:}

- Access to technical assistance to children showing some type of disability (children belonging to the $60 \%$ most vulnerable households of the country's population).

- Free access to a day care center or similar service (children whose mother, father or carer are working, studying or looking for a job belonging to the $60 \%$ most vulnerable households of the country's population).

- Free access to nursery school with extended working hours or similar service (children whose mother, father or caregiver are working, studying or looking for a job belonging to the $60 \%$ most vulnerable households of the country's population).

- Access to nursery school with part time working hours or similar service for children whose father, mother or carer are not working out of home.

- Guaranteed access to the "Supportive Chile" program to families with children under gestation who meet the access requirements stated by this social program.

\section{Preferred Access Services:}

These are specific services for families with children in early childhood of the $40 \%$ most vulnerable households of the country's population. They include: the Guaranteed family subsidy as of the fifth gestation month until the child becomes 18 years old, as long as they meet the requirements stated by law for this benefit (father and/or mother with no social security and be part of the $40 \%$ lower income population, which is to be certified by the application of the Social Protection Card).

Thus, families enjoy preferencial access to the public services offered according to the support needs for their children's development in programs such as: level-up courses, labor insertion, housing improvement and habitability conditions, mental health assistance, legal assistance, intra-family violence and child mistreatment prevention and assistance.

All the aforementioned services for the infant population can be seen below:

\begin{tabular}{|c|c|}
\hline $\begin{array}{c}\text { All children in early } \\
\text { childhood }\end{array}$ & $\begin{array}{c}\text { Massive } \\
\text { Educational } \\
\text { Program }\end{array}$ \\
\hline $\begin{array}{c}\text { Biological- } \\
\text { Psychological-Social } \\
\text { Development Support } \\
\text { Program }\end{array}$ \\
\hline $\begin{array}{c}\text { by the public health } \\
\text { system } \\
\text { Children of the } 60 \% \\
\text { most vulnerable } \\
\text { households }\end{array}$ \\
\hline $\begin{array}{c}\text { Children of the } 40 \% \\
\text { most vulnerable } \\
\text { households }\end{array}$ \\
\hline
\end{tabular}

Note. From "Chile Grows with You Website 2011"

Figure 3. Chile grows with You services coverage.

\section{Current Debates and Discussion}

The Chilean ECEC experience and its progress show the importance of the historical continuity of policies in a country and the role law plays to give such programs sustainability over time. Along with this is the influence of professionals in the field to publicize the contributions and progress made, raising awareness in decision makers with a powerful theoretical foundation so that their work may have a 
better basis upon which to grow.

In this paper, within the group of the professionals in this field comprising health area specialists and social protection specialists, among others, we have made special reference to specialized educators who work at this level, since in the case of Chile, their role has been critical for over a hundred years. Their role has not only been to make direct quality educational work possible with young children, but also to set up the right of young children to an age relevant education from birth.

At present, due to a tendency to instrumentalize education in early childhood as a result of the competition arising from international tests over some fields of learning, a large number of Chilean educators have reacted by joining the Declaration that the World Organization of Early Childhood Education made in Gothenburg, Sweden last year on the "Right of Children to Play and Learn by Playing".

As we have noted, upon permanently rethinking and re-examining early childhood education, there is concern about some specific regulations and programs that have arisen which contradict the great policies the country has developed in this field. This implies admitting that political interpretations are also subject to different emphasis depending on each person concerned. However, it should be noted that the national concern about education in general and in this field is already permanent, which in itself represents good progress as a country. This may be proved by the fact that they have been an explicit part of all the government programs of the last four presidential office terms.

It will be the work of the educators themselves to continue with their broad educational task for the family and the society, so as not to forget the sense and primary purpose of Chilean early childhood education, namely, full, trusting and happy development of young children in social and environmental scenarios that offer them an increasing number of better life opportunities.

\section{References}

Chile Grows with You. (2010). Comprehensive childhood protection system 2006-2010 report. Santiago, Chile: Puerto Madero.

Integra Foundation. (2006). 2000/2006 report. Santiago, Chile: Ograma.

JUNJI Board. (2005). 35 years working for Chile's children. Santiago, Chile: Andros Impresores.

Ministry of Education. (1998). Reform in progress: quality education for all. Santiago, Chile: Salesianos.

Ministry of Education. (2001). ECEC Curricular Bases. Santiago, Chile: Salesianos.

Ministry of Education., JUNJI Board., \& INTEGRA Foundation. (2005). Building up the children's future (2000/2006 Report). Santiago, Chile: Editorial Atenas.

O. E. I., UNESCO., \& SITEAL. (2010). Educational goals for 2021: Challenges and opportunities. Madrid, Spain: Trama.

Peralta, V. (2006-2010). Infant education history. (Vols. 1-5). Santiago, Chile: IIDEI, Universidad Central.

UNESCO., \& Ministry of Education. (2004). Learning from experience: ECEC curricular reform. Santiago, Chile: Trineo Publishing Co.

UNESCO. (2007). Solid bases: Early childhood education and care. Belgium.

UNICEF. (2000). Relevant indicators 2000 Chile. Santiago, Chile: Gráfica Andros Publishing Co.

\section{Notes}

1 JUNJI WEBSITE: “About us"

2 JUNJI WEBSITE. “Educational Programs".

3 Foundation WEBSITE: Integra Foundation Information

4 The "Education for All, 2007" UNESCO report states an average schooling of early school education and care of $62 \%$, but it corresponds only to the 3 to 6 age segment, which receives most of the service in the entire region.

5 Further information on www//mineduc.cl/Early Childhood Education and Care 